\title{
Apuntes sobre ciertas resistencias en el lenguaje: el género del español
}

Notes on Some Resistances in Language: The Gender of the Spanish Language

Victoria Scotto

DOI: https://doi.org/10.24215/25457284e120

Universidad Nacional de La Plata - CONICET,

Argentina

scottovictoria@gmail.com

Recepción: 12 Julio 2018

Aprobación: 08 Julio 2020

\section{Resumen:}

En este trabajo se abordará una cuestión central en la investigación lingüística contemporánea: la del lenguaje no sexista o "lenguaje inclusivo" y la intervención política de la Real Academia Española en esta cuestión. El objetivo de este trabajo es dar cuenta de una discusión centrada en la posibilidad de ejercer transformaciones en la lengua española con miras a cambiar algunas de las desigualdades estructurales que la integran. La metodología y teoría desde la cual se aborda el objeto es la glotopolítica: un modo de abordaje del estudio de la lengua que pone en foco el carácter político que constituye toda discusión sobre el lenguaje.

Palabras ClaVe: Lenguaje inclusivo, Lenguaje no sexista, Real Academia Española, Glotopolítica, Femicidios.

\section{Abstract:}

This study will address a central issue in contemporary linguistic research: gender-neutral language or "inclusive language" and the political intervention of the Royal Spanish Academy on this issue. The main purpose of this paper is to account for a discussion centered on the possibility of transforming the Spanish language, seeking changes in some of its structural inequalities. The methodology and theory employed for this analysis is Glotopolitics: a way of approaching the study of language that acknowledges the political level of every discussion regarding language.

KEYWORDs: Gender neutral language, Non-sexist language, Royal Spanish Academy, Glotopolitics, Femicides.

\section{INTRODUCCIÓN}

El rol tutorial que tiene la Real Academia Española (RAE) hoy tiene un peso relevante: pesa a les académiques $^{1}$ en la búsqueda de autoridades, pesa a les hablantes que tienen al español como lengua materna o segunda y extranjera al buscar definiciones. Quizás no haya diccionario en esta lengua más consultado que el Diccionario de la Lengua Española (DLE) de la RAE, como no hay examen más legitimado de conocimiento de la Lengua Española que el que ofrece el Instituto Cervantes. El profundo grado de peninsularidad de las autoridades más comúnmente reconocidas expresa una permanente referenciación en relación a España por parte de la lengua que más se habla en Latinoamérica.

Esa vigencia se contrapone a la antigüedad que precede, por ejemplo, a la Real Academia Española, que fue fundada en 1713. Es válido discurrir acerca de cómo ha funcionado a lo largo de la historia como instancia disciplinadora frente a los cambios emergentes de la lengua. Incluso, es posible hacerse la pregunta sobre cuán anquilosada es de por sí una institución que busca "fijar" la lengua, o "limpiarla”. Sin embargo, su vigencia es altísima y, sobre todo, reclama para sí niveles de actualización y pluralismo que invitan a pensar si después de trescientos siete años no se habrá adaptado a los tiempos que corren. Las entradas del Diccionario de la Lengua Española son los primeros resultados en todas las búsquedas de Google de palabras que estén incluidas en él; la aplicación de la RAE tiene más de 1 millón de descargas sólo en el sistema operativo Android. ${ }^{2}$ No es ni por asomo una institución susceptible de ser ignorada ni está fuera de juego en "la batalla de la lengua" (como la piensan Del Valle y Stheeman, 2004), sin embargo, hay un grado significativo de engaño en esa pretensión de pluralidad y en esa actualización. 
La importancia que tiene el estudio de la dimensión política de los roles de las instituciones que giran en torno a la lengua española está centrada especialmente en estudiar al lenguaje en su dimensión social y como un terreno de disputas de poder. La perspectiva de la que parte el presente artículo para reflexionar sobre el lenguaje es, precisamente, la glotopolítica. Sobre ella, dice Elvira Narvaja de Arnoux:

La Glotopolítica estudia las intervenciones en el espacio del lenguaje, entendidas estas en un sentido amplio ya que pueden ser planificadas, explícitas, voluntarias, generadas por agentes - colectivos o individuales - que podemos identificar, o producidas “espontáneamente" sin mediadores claramente identificables (Arnoux, 2016, p. 19).

Así, no sólo interesan las transformaciones que, de hecho, ocurren en las lenguas sino las intervenciones políticas que sobre el espacio del lenguaje se producen a partir de voluntades institucionales, particulares o colectivas, que permiten dar otra dimensión de análisis al estudio de la lengua como hecho social. En este sentido, como Arnoux, se considera aquí que la historia de las intervenciones políticas también conforma la historia de la lengua en sí misma.

No abordamos los instrumentos lingüísticos primariamente por su posible ubicación en una Historia de la Lingüística o, incluso, en una más amplia Historia de las Ideas sobre el Lenguaje sino por su inscripción en los procesos históricos y en especial en lo que corresponde a su dimensión política. (...) Pero esos instrumentos nos interesan fundamentalmente como indicios de transformaciones en curso o de toma de posición de un sector social, como formas de reproducir la estructura de clases dominante o como expresión de una voluntad de cambio. De allí la importancia del abordaje discursivo de los materiales que nos va a permitir reconocer regularidades, identificar asociaciones, atender a fenómenos periféricos pero significativos que orienten en ese sentido la interpretación (Arnoux, 2016, p. 20-21).

Partiendo de esta concepción de lengua y de esta voluntad de análisis, lo que se busca explorar en este trabajo son algunas de las intervenciones políticas de la RAE en relación a fenómenos específicos como la aceptación de algunas palabras dentro del DLE o el reconocimiento de las diversas manifestaciones de lo que se conoce como "lenguaje inclusivo".

La RAE utiliza diversas herramientas para avanzar en estas intervenciones políticas. Entre ellas, no solo se encuentran las entrevistas que frecuentemente ofrecen sus académicos a distintos medios, o el lugar que tienen en la prensa las inclusiones lexicales de sus ediciones del diccionario. La publicación regular de los Diccionarios, las ediciones que la Academia hace de ciertas obras literarias en ediciones críticas, las obras académicas, y su biblioteca y archivo quizás sean las más prestigiosas. Sin embargo, también, es preciso mencionar una herramienta digital permanente, con visibilidad y constantes intervenciones públicas: la cuenta@RAEinforma de Twitter, a la que cualquier usuarie puede consultar utilizando el hashtag \#RAEconsultas. En este trabajo se analizarán intervenciones políticas de miembros de la RAE y de la RAE como institución realizadas a través de la prensa digital, el DLE, la cuenta de Twitter@RAEinforma y las herramientas que ofrece el sitio web http://www.rae.es. Se presupondrá, en este análisis, que estas intervenciones están atravesadas por la política panhispánica que sostiene la RAE, expuesta en su página web ("Política panhispánica", 2020), como forma de expresar un posicionamiento orientado a la unificación de las diversas variedades del español presentes en Europa y América. Según esta política panhispánica es voluntad expresa de la RAE que tode hablante de la lengua española se referencie, de alguna u otra manera, en los materiales que produce su institución.

Parte de este panhispanismo se advierte en la alta referencialidad de un material específico de la RAE, el ya mencionado Diccionario de la Lengua Española. Las discusiones suscitadas en la prensa en función de qué vocablo la RAE acepta y cuáles no, según explica Daniela Lauría (2015), forman parte de una diccionarización de la lengua: gran parte de las consultas que se realizan a la RAE tienen que ver con discusiones de vocabulario, y justamente en esta tradición lexicográfica se despliega un espacio de conflictos y contradicciones que, en el caso americano, no puede evitar ligar sus disputas al poderío que aún representa Madrid (Lauría, 2015, p. 70). Por lo menos en los últimos años las discusiones sobre qué incluye y qué no incluye la RAE en sus diccionarios tienen lugar en la prensa: interesa qué habilita la RAE a decir y qué no, qué puede ser nombrado y qué debe ser 
relegado a la oscuridad de lo inaudito. Las grandes intervenciones de la RAE en las discusiones sobre la lengua, en general, tienen que ver con la inclusión o el rechazo de formas del habla popular (ya sea morfológicas o léxicas) en sus obras: el Diccionario de la Lengua, el Panhispánico de Dudas y el de Americanismos como los más conocidos.

La presencia en la prensa de aquello que la RAE aprueba o deja de aprobar implica una inserción de las voces "autorizadas" en debates propios de lo que puede o no decirse en la cotidianeidad, fundamentalmente a propósito de los modos de expresión de realidades que fueron transformadas en las últimas décadas. Es decir: aquí interesan fundamentalmente las reacciones de esta institución en cuestiones de agenda pública, como la relación de los feminismos con el lenguaje. Se incluirá aquí una serie de respuestas y posicionamientos en torno a lo que se conoce usualmente como "lenguaje inclusivo", así como la inclusión o exclusión de los términos "femicidio" y "feminicidio", "feminazi" y "hembrismo".

Lo que se intentará demostrar en este trabajo es que las intervenciones políticas que realiza la RAE para regular, dentro de sus instrumentos, algunas de las manifestaciones lingüísticas de la lucha de los feminismos en la lengua sostienen una voluntad reaccionaria, colonial y patriarcal de no dar cuenta de la pérdida de vigencia de su normatividad.

\section{Estudios DE CASO}

Se abordarán aquí dos grandes ejemplos del abordaje de la relación entre las manifestaciones lingüísticas de la militancia feminista y la RAE: el llamado "lenguaje inclusivo" 3 y la inclusión o exclusión del diccionario de ciertos usos léxicos.

\subsection{Todas, todes, todxs, tod*s, tod@s: ¿̇todos?}

En el caso del "todos y todas", hace ya años que en Argentina la opinión pública convive con la disputa por los modos en los cuales es posible profundizar la inclusión de las feminidades y diversidades sexogenéricas dentro de la lengua española, sobre todo en las formas en las que se reseñarán a continuación. La opción más popularizada durante el kirchnerismo correspondió a la duplicación de las formas nominales para incluir dentro de las generalizaciones a grupos de mujeres: el resultado fueron las formas "todos y todas", "ciudadanos y ciudadanas", "compañeras y compañeros", entre otras. De manera simultánea, las universidades españolas empezaron a resolver las mismas inquietudes a partir de debates internos que atendían sobre todo a las exigencias emergentes del movimiento feminista: se produjeron así guías de lenguaje no sexista propuestas por nueve academias. ${ }^{4}$ Un gran ejemplo de ellas es la de la Universidad de Granada, que incluye una justificación a propósito de la presencia del sexismo en el lenguaje. En la guía se sugiere la implementación de un lenguaje que evite los masculinos "mal llamados genéricos", y se propone insistir en la visibilización de la mujer mediante la utilización de sustantivos colectivos de género indeterminado (reemplazar "los profesores" por "el profesorado"), la duplicación de sustantivos para incluir a los femeninos cuando no sea posible la utilización de sustantivos colectivos ("los y las profesores y profesoras", forma de expresión no marcada en la lengua alemana, por ejemplo) o la utilización de la barra para marcar lo mismo ("los/las profesores/as"). En el caso de la Universidad de Granada también se considera el uso de la arroba ("profesor@s") por una cuestión de popularidad: sin embargo, es importante señalarlo, en ningún caso se considera la utilización de cruces, la letra "e", la arroba, o la forma femenina como estrategia de inclusión de las identidades no binarias en el discurso.

La escalada de institucionalización del lenguaje no sexista, tanto en Latinoamérica como en España, ameritó la publicación del primero de marzo de 2012 denominada "Sexismo lingüístico y visibilidad de la mujer”, redactada por Ignacio Bosque y firmada por 26 miembros de la Real Academia Española. Contiene 
una crítica a las guías de lenguaje no sexista de las nueve universidades publicadas en los meses anteriores, bajo la idea de que si bien las premisas que sustentan dichas guías son correctas no lo son también las conclusiones (Bosque, 2012, p. 4). Las premisas corresponderían a una (señalada como cierta) desigualdad entre hombres y mujeres que se manifiesta en el lenguaje, dice Bosque, sólo porque precisamente el lenguaje permite expresar cosas como "Los directivos acudirán a la cena con sus mujeres" (entendiendo que las mujeres no son de nadie). Aclara Bosque: es una "confusión" exponer que hay sexismo en la frase "todos los que vivimos en una ciudad grande", porque hay "acuerdo general entre los lingüistas en que el uso no marcado (o uso genérico) del masculino para designar los dos sexos está firmemente asentado en el sistema gramatical del español”. Hay que resaltarlo: Bosque no dice que el genérico es la letra "o": dice que el que incluye "a los dos sexos" es el género masculino. Ya desde ahí, Bosque demuestra hasta dónde lo que él marca como la aclaración de una confusión es en verdad un duro reducto de defensa del patriarcado lingüístico: cuando dice masculino, evidencia que dentro de su argumento está el reconocimiento del sexismo de la morfología del español. ${ }^{5}$

Pero hay aún otras notas que hacer a las declaraciones de Bosque: equipara la representación del género (ya sea morfológico o individual) con el sexo, palabra que parece designar (no se comprende bien si al fenotípico, genotípico, genital o qué tipo de dimensión) lo que a veces suele nombrarse, de manera un tanto simplista, como "sexo biológico". ${ }^{6}$ Bosque, en este texto, no parece saber no sólo que existen más de "dos sexos" sino que más allá de esta realidad, ni siquiera es posible equiparar las categorías de género y sexo, en ningún caso, y que es precisa muy poca formación en la materia para advertir que se tratan de nociones que representan características distintas de una misma persona (Rose, Lewotin y Kamin, 1990).

Las retrógradas e ignorantes declaraciones de Bosque generaron una resistencia no sólo extendida y evidente, sino ante todo prolongada. Respuestas diversas (Cabeza Pereiro y Rodríguez Barcia, 2013; Cano y Yacovino, 2015; Becker, 2019) se pronunciaron a propósito de los diversos usos posibles para comenzar a nombrar aquello invisibilizado por la "neutralidad" del masculino señalada por Bosque: sea la cruz, la arroba, el asterisco o la letra e, o varias otras posibilidades quizás menos exploradas, las nuevas formas de dar lugar en medio de la lengua patriarcal a la diversidad de género se han vuelto instancias de resistencia a una academia que no deja de reclamar para sí una herramienta que no puede ser "fijada", y que brilla con esplendor propio.

\subsection{Femicidio/feminicidio: jurisprudencia sobre una palabra}

El caso de la inclusión de palabras como "feminicidio" representa otro capítulo de la historia de las disputas lexicográficas. La inclusión o exclusión de neologismos en el Diccionario de la Lengua Española implica una decisión "discursiva, ideológica, histórica", porque la identidad lingüística "no es permanente, a-histórica, [ni posee] rasgos universales" (Lauría, 2015, p. 70). La inclusión de "feminicidio" en el DLE está ligada a la acción de los movimientos feministas en España y Latinoamérica: no se incluye en el diccionario cuando, en 1980, Diana Russell publicó por primera vez un libro que se utilizaría en derecho para promover agravantes en criminología para los crímenes de odio contra la mujer; no se incluye cuando Marcela Lagarde (1997), en México, traduce no sólo el libro, sino también el concepto para las indicaciones sobre agravantes del derecho latinoamericano. Se incluye en 2014, cuando ya seis países latinoamericanos (México, Chile, Argentina, Ecuador, Bolivia y Honduras) contaban con leyes que incluían al femicidio o feminicidio como agravante de crimen de odio, cuando en Argentina se creaba el Registro Nacional de Femicidios de la Justicia Argentina, se redactaba una guía de lenguaje no sexista para la Honorable Cámara de Diputados de la Nación y la organización Periodistas de Argentina en Red por una Comunicación no Sexista elaboraba un decálogo de tratamiento de noticias vinculadas a violencias hacia la mujer para no perpetuar estereotipos violentos (Carbajal, 2012). Aun teniendo una fuerte legitimación por parte de uno de los lenguajes más conservadores de la sociedad, el lenguaje jurídico, no se registra "feminicidio" sino hasta que el término estuvo en "agenda" 
y tuviera significativas menciones en el periodismo latinoamericano y europeo, mucho después de que se lo reconociera culturalmente, y años después de que contara con profusa literatura legal detrás de sí.

\subsection{Hembrismo y feminazi: nombrar lo que no existe}

No es el caso de la inclusión de "hembrismo" y "feminazi". Son palabras que se intentaron incluir en 2016, muy cerca temporalmente de sus primeros usos masivos en las redes, ${ }^{7}$ después de que grandes avances del movimiento feminista generaran reacciones violentas (frecuentemente, organizadas) por parte de sectores reaccionarios de la comunicación. No hay literatura sobre estos términos más allá de las redes sociales (y los pocos comentarios periodísticos al respecto): los resultados que arroja Google para la palabra "feminazi" son 584.000; los de "hembrismo" son apenas 152.000; los de "feminicidio" son 1.760.000, y los de "femicidio", 1.040.000. En inglés, la palabra "femicide" tiene 430.000 resultados, y "hembrism" apenas 1200. Es claro que no es posible ni siquiera empezar a comparar el alcance del primer término con los otros dos. Y sin embargo, las tratativas para la inclusión en el Diccionario de la Lengua Española comenzaron para "hembrismo" y "feminazi" y están documentadas ${ }^{8}$ a pesar de que se tuvo que echar atrás su oficialización a partir de las polémicas que generaron, fundamentalmente por carecer estas palabras de un sostén epistemológico, y por ser simplemente palabras inventadas ad hoc para atacar a los movimientos feministas.

¿Cómo incluye neologismos en su diccionario la RAE? Fundamentalmente por medio de dos procedimientos: las propuestas de les académiques, y el portal UNIDRAE, una instancia interactiva en la cual cualquier persona puede "sugerir" la inclusión de una palabra, que luego será evaluada por las comisiones pertinentes (portal que, al momento de redacción de este trabajo y durante casi todo el año 2018 y parte de 2019 permaneció cerrado). ${ }^{9}$ Blecua, miembro de la Academia, propone en una entrevista en Casa de América (Blecua, 2014) que "el diccionario es un reflejo de la lengua en el estado actual": explica que el espíritu de la inclusión de neologismos tiene como propuesta fundamental retratar de manera fiel la riqueza y pluralidad de la lengua. Ahora bien: el funcionamiento real de la inclusión de neologismos implica una selección previa y, en este sentido, no se hace un registro total de las formas del estado actual de la lengua. ¿Por qué esperar más de treinta y cuatro años de su uso en la literatura legal para aceptar "feminicidio" y comenzar tratativas para incluir "feminazi" y "hembrismo", que en 2008 tenían menos 1100 resultados en Google? Hay un elemento interesante: mientras que ningún miembro de la RAE registró jamás en redes el vocablo "feminicidio" o “femicidio" (que no está aceptado), Arturo Pérez-Reverte, que ocupa el sillón “T” en la Real Academia, sí usó en Twitter la palabra "feminazi” (Arturo Pérez Reverte, 2012; Ruiz Mateo, 2012), varias veces.

\section{INSTITUCIONALIZACIÓN DE LAS PALABRAS}

Necesariamente las inclusiones de formas en un diccionario son elecciones políticas: ya sean americanismos, o "peninsularismos" (palabra que no figura en el diccionario), es innegable que cada "legislación" que la RAE pretende operar en su lengua limpia e institucionalizada es eminentemente política. La pregunta sobre la lengua desde los inicios mismos de la Lingüística como disciplina incluye dentro de sí la pregunta por la "lengua" y el "uso". Es decir, la disyuntiva sobre dónde hacer pie para comenzar a analizar: si tomar una "lengua" estratificada, estándar, en boca de une hablante ideal, planteada como objeto de análisis recortado y aislado y ejemplar, o si registrar como objeto el "uso", la dimensión más viva posible del lenguaje, la instancia de expresión y comunicación más presente en las vidas de las personas. En este sentido, la decisión de registrar como lengua un constructo ideal o un conjunto de usos reales es sin lugar a dudas una discusión de carácter político. Optar por incluir todo lo dicho y expresado (feminicidio y femicidio, y feminazi y hembrismo) es una decisión que implica sus difíciles consecuencias, pero conlleva en sí el sentido de un compromiso con la lengua "real"; decidirse por hacer figurar únicamente aquello que se quiere que exista, en términos normativos, es 
otra muy distinta. Y en términos de incluir neologismos, los antecedentes de la Real Academia son claros a propósito de cuál ha sido, a lo largo de la historia, su posicionamiento: la RAE "limpia”, según expresa su lema.

En su trabajo "Lo que la RAE no nombra no existe: una mirada glotopolítica a las respuestas de la RAE al lenguaje inclusivo/no sexista”, dice Niklison (2020) que la importancia de la institucionalización de ciertas palabras o, en el caso del lenguaje inclusivo, de una transformación morfológica, radica en reforzar la entidad y validez dentro de las academias lingüísticas de un universo de discusiones que ya son parte de la realidad. Entendiendo la relevancia de la RAE en su rol no sólo descriptivo sino normativo (Del Valle, 2011), el peso la aceptación de las intervenciones que los feminismos realizan sobre el lenguaje está íntimamente vinculada al carácter institucional de una academia que, desde su gestación, cumple un rol en nombrar lo que existe. Niklison expresa que "lo que la RAE no nombra no existe", y en términos de lo que para ciertos sectores significa la RAE, tiene razón: el poder de aceptar en un volumen de codificación de la lengua española los debates sobre cómo hablar de personas, hechos o posiciones que existen es altamente relevante en la medida en que es un reconocimiento de entidad a esos sujetos que necesitan ese reconocimiento institucional en el que ya no tienen que ser la excepción que no merece ser nombrada sino parte de lo existente.

\section{UNA LECTURA GLOTOPOLÍTICA SOBRE LOS ESTUDIOS DE CASO}

Existen posicionamientos a este respecto, quizás representados cabalmente en Argentina por las declaraciones públicas de Beatriz Sarlo $(2018$; 2019) pero también por algunos académicos españoles (Fernández Rivero, 2017), que indican que las transformaciones en la lengua solo pueden darse a partir de procesos "no impuestos". El principio que subyace a esta premisa indica que el lenguaje no es susceptible de ser afectado a partir de las intervenciones políticas; es decir, propone que no existe un intervencionismo lingüístico que resulte exitoso en el mediano o largo plazo. Sin embargo, esta posición, que parece echar por tierra la posibilidad de alentar transformaciones o inserciones lexicográficas en la lengua y que esto redunde en un cambio en ella, presupone que el lenguaje inclusivo o no binario no parte de una demanda social, no parte de un colectivo existente y que, a través de ir ganando visibilidad social, reclama su lugar en la lengua registrada o normada a través de instrumentos gramaticales o lexicográficos. Si efectivamente es voluntad de la RAE registrar en su diccionario los usos extendidos, y el debate a propósito del lenguaje inclusivo está precisamente extendido al punto de que salen a pronunciarse por su rechazo con cierta regularidad desde hace ya años, ¿por qué no incluir "todes" al menos como modismo? Si es apenas un registro de usos, ¿por qué no incluir una definición de "travesti" en el diccionario que no defina a ese colectivo como "persona que se viste y caracteriza como el sexo contrario"? ¿por qué no ingresaron ya al DLE en 2020 los términos "no binario", "mujer trans" o "varón trans", si son usos plenamente extendidos? ${ }^{10}$

Es claro que hay una decisión tomada de antemano a propósito de qué usos registrar y qué usos no son considerados (no lo suficientemente extendidos, sino fundamentalmente) adecuados para figurar en los instrumentos descriptivos de la lengua de la RAE. Hay una relación directa entre resistirse y esperar al uso en léxico legal de "femicidio" y "feminicidio", negar la existencia de "mujer trans" (y reconociendo "travesti" como "hombre que se viste como alguien del sexo opuesto") y responder públicamente que "feminazi" designa a una "feminista radicalizada".

Las instancias de legitimación del "cómo se debe hablar" y "cómo es la lengua" se dan en gran medida en medio de lo que Del Valle y Stheeman (2004) llaman "el espectáculo de la lengua", que se compone por tiradas de prensa de artículos de opinión a propósito de la "corrección" de la lengua, la forma en la que las instituciones enseñan el español, artículos de divulgación o específicos y una larga lista de etcéteras. Les actores de este espectáculo son tanto les filólogues y lingüistas de renombre que ocupan sitios en academias como empresaries y figuras públicas. En este espectáculo 
se desarrollan los debates acerca de la estandarización lingüística a nivel panhispánico y las formas de protesta acerca del "descuido" en que los hablantes tendrían la lengua española, que constituirían la base de un proceso de recuperación de la autoridad pública del experto en tales asuntos (con la Real Academia Española como institución de mayor prestigio dentro de esa constelación), lo cual muestra para los autores una de las formas de intentar orientar el cambio lingüístico en forma centrípeta. Esta concepción de una élite lingüística con tales funciones es entendida por ellos como característica de una representación de la comunidad lingüística dentro de las culturas monoglósicas envueltas en procesos de estandarización (Ennis, 2008, p. 23).

Entonces, si la "batalla de la lengua" se da entre una multiplicidad de autores y, según Del Valle y Stheeman, una infinitamente mayor cantidad de hablantes con(tra) quienes se establece "el modelo a seguir", las condiciones de desarrollo de esa batalla implican una violencia lingüística fundamental que se impone a les hablantes desde la más tierna infancia. Las lógicas establecidas desde estos discursos hegemónicos, sin embargo, no son meramente puristas, es decir, no les interesa la "belleza" del lenguaje, como si genuinamente les representantes de las cátedras de la Real Academia se sintieran en poder de la verdad de la belleza lingüística. Les interesa, al decir de Ennis, consolidar la fuerza centrípeta de desarrollo del lenguaje. Y ese centro, claro, para estas instituciones, debería ser Madrid.

Leer Linguistics in a colonial world de Joseph Errington, en este contexto, es darle al análisis del lenguaje contemporáneo una veta histórica, que aquí resulta particularmente relevante: expone que ante todo estas lógicas, que Del Valle (2004) ve como panhispanistas, ${ }^{11}$ pesan en América por ser eminentemente colonialistas: la ideología imperial española instalada en Hispanoamérica terminó por confirmar el plan, que llega hasta hoy, de una "historia de los destinos preasignados a los orígenes" (Errington, 2008, p. 17): es decir, hecha la historia de la superioridad europea, hecho el eterno destino colonial de los países americanos. Esto incluyó una propia "moral legitimadora para las naciones europeas en un mundo que estaban comenzando a dominar" (p. 17), moral que no sólo se instala sobre el culto sobresaliente a la erudición europea, sino que ordena la "descendencia" lingüística como una reproducción en términos de lenguaje y de cultura que termina por, naturalmente, establecer la eterna dependencia de las naciones hispanoamericanas de la cultura española, quien resultaría una eterna referencia obligada.

Pero lo que no es posible olvidar en este contexto es que el lenguaje lo usan para pensar y para expresarse personas reales con identidades e historias reales. La influencia del lenguaje inclusivo en la visibilización y garantía de derechos de un colectivo oprimido no sólo tiene efectos a nivel institucional en el reconocimiento de esas identidades, sino que comienza un largo proceso de reconocimiento y reparación de siglos enteros de invisibilización. Reivindica un nombre, lo pone de manifiesto, le da un lugar.

Existen trabajos que dan cuenta de la relación que existe entre el género gramatical de los sustantivos que designan a ciertos objetos y la concepción que las personas tienen de ellos (Phillips, 2003); trabajos que estudian la relación directa que se establece entre el masculino (supuestamente) neutro y el "verdadero" masculino (aquel que menciona meramente a grupos masculinos y no pretende nombrar nada más) (Cooper, 1997); y análisis de comportamiento de sujetos en situaciones de ausencia o presencia de representatividad de la diversidad de género en contextos profesionales (Stout y Dasgupta, 2011); todos llegan a la misma conclusión: la representación gramatical del género es un elemento que influye y puede hasta condicionar el la percepción de la realidad y de las personas que se vinculan en ella. ¿̨Por qué entonces renunciar a la intervención que, en todo caso, es posible intentar para asegurar la máxima representatividad y equidad en la forma de nombrar personas? Si se entiende aquí a la lengua como un dispositivo en el cual se producen intervenciones políticas con miras a establecer relaciones de poder, ¿cómo no intervenir sobre la lengua para democratizar su poder de representatividad? Y en todo caso, quienes se resisten a esta representatividad, ¿qué noción de la lengua y de la realidad están sosteniendo? 


\title{
5. CONSIDERACIONES FINALES: CONSOLIDAR LA FRACTURA, LEGITIMAR LA DIVERSIDAD
}

Consolidar lógicas coloniales, reales (es decir, monárquicas), implica frecuentemente consolidar lógicas patriarcales. Como lo ha dejado en claro Foucault en Vigilar y castigar (1975), las sociedades occidentales contemporáneas siguen persiguiendo el objetivo de disciplinar los cuerpos como estrategias de establecimiento del orden y la perpetuación de su propio sistema. Luego, la inserción de la noción de "biopoder" en La voluntad de saber (1984) complementa la idea del control de los cuerpos para comprender dentro de sí la estructura de sumisión de las identidades femeninas. Jacques Derrida, a fines de los años 80, instala la crítica al "falogocentrismo" para denunciar las lógicas culturales binarias, centradas en la escritura, metafísicas y patriarcales, que resultan en sí una instancia de interpretación de los signos de la cultura para diseñar protocolos y estrategias de deconstrucción (De Peretti, 1989). Esto ocurre fundamentalmente porque la detección de lógicas coloniales, eurocéntricas y logocéntricas, tomadas desde un foco crítico, proponen consigo críticas a otras formas de la opresión imbricadas en las anteriores, como el patriarcado. Así, la institucionalización del lenguaje, o bien el lenguaje al servicio del biopoder, está íntimamente vinculado con las formas que el colonialismo tiene de oprimir cualquier forma de disidencia sexogenérica.

El español, como la lengua de la Real Academia, tiene, sin dudas, género. Dicen Deleuze y Guattari (1972):

\begin{abstract}
Supongamos que la constante o el patrón sea Hombre-blanco-macho-adultourbano-hablando una lengua standard-europeoheterosexual cualquiera (el Ulyses de Joyce o de Ezra Pound). Es evidente que "el hombre" tiene la mayoría, incluso si es menos numeroso que los mosquitos, los niños, las mujeres, los negros, los campesinos, los homosexuales..., etc. Y la tiene porque aparece dos veces, una vez en la constante, otra en la variable de la que se extrae la constante. La mayoría supone un estado de poder y de dominación, y no a la inversa. Supone el metro-patrón y no a la inversa (p. 107).
\end{abstract}

Es decir: la lengua que funciona como "patrón” (y esta palabra, entre todas, tampoco es casual), tiene género masculino, blanco, adulto, habitante de la ciudad, hablante de una lengua estándar europea, heterosexual. Tiene el género del deber-ser de la colonia, de la hegemonía: los hablantes son lo estándar (blancos, citadinos, adultos) y la lengua es heterosexual porque se vuelve un constructo que sólo reafirma el patrón hegemónico, porque sólo nombra, y por lo tanto hace posible, lo masculino heterosexual. Las personas hablantes de la lengua son innegablemente oprimidas por el mismo sistema biopolítico que instala un deber ser que direcciona su expresión dentro de las posibilidades de lo que puede "ser dicho", y fundamentalmente, quienes se inscriben fuera del paradigma del biopoder patriarcal, necesariamente son excluides también por una lengua que niega su existencia y consolida la norma de manera permanente.

Pensar con estrategias descolonializadoras, antipatriarcales, implica no tanto sustraerse de las lógicas del control institucional a los cuerpos como encontrar espacios para hacer estallar sus esquemas de control. Operar como un rizoma en medio de una lógica de poder arbórea permite, según Deleuze y Guattari, el desarme de una zona de la máquina, de un signo del falogocentrismo derridiano, de una zona de sujeción del cuerpo según Foucault.

Desandar las lógicas del control, como toda deconstrucción, implica elaborar observaciones desde dentro del constructo cultural para hacerlo implosionar: en el caso de la lengua, la atención a los propios procedimientos de desarrollo de la institucionalización de una palabra permite empezar a desarmar nudos de un sentido conservador y anquilosado. Y este desandar o hacer estallar el sentido consolidado del lenguaje, en este caso, no tiene como objetivo la mera denuncia, ni tiene como resultado la anulación de sus efectos, sino que permite la visualización de las marcas que el lenguaje ejerce sobre los cuerpos, y, al tiempo, evidencia las resistencias que insistentemente se practican desde todo ejercicio de la lengua. Nada de esto es nuevo, el posestructuralismo nos ha legado este paradigma de investigación hace ya más de cincuenta años.

Y, sin embargo, los contextos de visibilidad y de disputa que hoy trazan la política de género son otros. ¿Por qué comenzar con la Real Academia Española? ¿No es a esta altura una institución vieja, de nuevo, anquilosada, dejada atrás por la mera irrupción de la era digital, que la dejó obsoleta? En ninguna forma. Hoy, más que nunca, es preocupante y ameritan discusión la vigencia del diccionario como instancia 
normalizadora, las actualizaciones de la plataforma web y de las aplicaciones para celulares, y el discurso de pluralidad que precede a una Academia que insiste en que la península es la norma y toda la América de habla hispana, un territorio casi veintitrés veces más grande, es el caso marcado. La pretendida política panhispánica de la RAE, en este sentido, no es tal: a pesar de insistir en su voluntad de representatividad en relación a todes les hablantes del español, incluso les americanes, insiste en poner, como límite de la tolerancia a las variedades lingüísticas americanas, la marca de lo alterno, la palabra que señala, en el diccionario, la barbarie: "americanismo", recordando que la forma "neutral" de hablar es la peninsular, del mismo modo que la manera "neutral" de tener un género es la de identificarse con el género masculino.

Esta institución, tan reacia a transformarse junto con el mundo, permanece en constante actualización en términos tecnológicos como forma de seguir haciéndole saber a tode hablante de la lengua española cómo "debería" hablar. Ya lo han dicho una inmensa cantidad de autores que estudian el gran universo de la glotopolítica (Arnoux, del Valle, Ennis, Lauría, entre muchísimos otros): estas instituciones detentoras de una cierta verdad sobre el lenguaje representaron al poder monárquico y colonial en función de permanecer adheridas a las sucesivas reparticiones del poder político y económico. Al patriarcado, un sistema con más de ocho milenios de historia de opresión (Lerner, 1990) también se adhirió, sostenida como una institución sólo de varones. La defensa del statu quo no se expresa en la RAE en un manifiesto sino en decisiones políticas, en posicionamientos particulares y en la repetida vocación de defender su ubicación como guardiana de la lengua, desde una pretendida inocencia y neutralidad que se anuncia como simple registradora de sucesos de la lengua.

Pero no hay nada menos neutral que la Real Academia Española. Y en esta imagen casi tecnócrata que la RAE reclama para sí, se desliza el poder que detenta, y cómo su "puesta al día" en la era digital, cómo su pasaje del libro a la pantalla, cómo la falsa ilusión de participación que crean el UNIDRAE y la inclusión de americanismos, son métodos para aumentar su participación en la lucha de poderes que es toda lengua. Detrás de los cuarenta y cinco sillones de la Academia, empresas reconocidas (Repsol, Telefónica, La Caixa, por sólo nombrar algunas) sustentan la actualización tecnológica de la misma ideología decidida a proteger el statu quo más rancio.

Se trata de una caricatura de renovación de una institución que en sus más de trescientos años ha contenido dentro de sí a cuatrocientos sesenta y cinco varones y a once mujeres, que contiene en sus filas a académicos abiertamente no feministas como Arturo Pérez-Reverte (Arturo Pérez Reverte, 2012; Ruiz Mateo, 2012) o Javier Marías (2017a; 2017b; 2018a; 2018b), y que hoy anuncia, a través de su vocero José María Merino, que "no es machista ni poco feminista" (Martín Barranco, 2019). La Academia se ve obligada a responder en un momento en que la política global demanda que aborde el problema del género, y su respuesta busca mantener un discurso "totalmente abierto" (citando de nuevo a Merino) al tiempo que sostiene el normativismo del lenguaje como último reducto conservador, colonialista y patriarcal. Y sostienen ese normativismo no sólo porque, como dice Ignacio Bosque, el lenguaje puede "decir cosas machistas", sino porque la lengua española "bien hablada", consolida, sostiene, legitima e institucionaliza el patriarcado una y otra vez, a fuerza de repetición. Dice Roland Barthes, con diáfana razón: "La lengua es fascista: no por lo que impide decir sino por lo que obliga a decir" (Barthes, 1982, p. 64); precisamente estas instituciones obligan una y otra vez a decir aquello que no se quiere decir, a reducir al mundo a sus lógicas coloniales y patriarcales. Luchar contra ese fascismo es, fundamentalmente, visibilizar: visibilizar las identidades femeninas, diversas y disidentes, las desigualdades estructurales, las opresiones históricas. Visibilizar es también el resultado de la lucha, y una necesidad de primera orden para empezar a trazar los contornos, al menos lingüísticos, del innegable reconocimiento que se les debe a las identidades olvidadas de siempre. La justicia, también, deberá hacerse desde el lenguaje.

¿Cómo batallar contra ese reducto? Encontrando espacios para hacer estallar el sentido de la lengua española de la RAE, molestando con indagaciones filológicas y lingüísticas que hagan temblar el sentido común que anuncia que no hay nada que cuestionar. Abriendo el uso académico a diferentes posibilidades 
y logrando institucionalizar formas de nombrar lo que existe, sin caer en la resignación de un solipsismo lingüístico. Recuperando la libertad de la expresión lingüística como instancia soberana de desarrollo de una cultura, reivindicando los derechos lingüísticos como derechos humanos y consolidando espacios que habiliten la reflexión sobre por qué vale la pena tomar posición consciente dentro de la batalla del idioma.

\section{ReFERENCIAS}

Arnoux, E. N. de (2016). La perspectiva glotopolítica en el estudio de los instrumentos lingüísticos: aspectos teóricos y metodológicos. Matraga, 38, 18-4.

Barthes, R. (2003 [1982]). El placer del texto y Lección inaugural de la cátedra de semiología literaria del Collège de France. Buenos Aires: Siglo XXI.

Barranco, M. (2019). Ni porfavor ni porfavora. Cómo hablar con lenguaje inclusivo sin que se note (demasiado). Madrid: Los Libros De La Catarata.

Becker, L. (2019). Glotopoli\#tica del sexismo: ideologemas de la argumentación de Ignacio Bosque y Concepción Company Company contra el lenguaje inclusivo de género. Theory now, 2(2), 4-25.

Blecua, J. M. (2014) Conversatorios en Casa de América. Recuperado a partir de http://www.casamerica.es/literatur a/el-diccionario-es-un-reflejo-de-la-lengua-en-el-estado-actual

Bosque, I. (2012). Sexismo lingüístico y visibilidad de la mujer. S/D. Recuperado a partir de https://www.rae.es/site s/default/files/Bosque_sexismo_linguistico.pdf

Bravo Sueskun, C. (2010). Guía para un uso del lenguaje no sexista en las relaciones laborales y en el ámbito sindical. Secretaría Confederal de la Mujer de CCOO. Recuperado a partir de https://www.ccoo-servicios.es/archivos/ Guia_para_un_uso_del_lenguaje_no_sexista_en_las_relaciones_laborales_y_en_el_ambito_sindical.pdf

Cabeza Pereiro, M. C. y Rodríguez Barcia, S. (2013). Aspectos ideológicos, gramaticales y léxicos del sexismo lingüístico. Estudios filológicos, 52.

Cano, J. y Yacovino, M. L. (2015). Una respuesta a 'Sexismo lingüístico y visibilidad de la mujer' de Ignacio Bosque. Desgenerando el género. Recuperado a partir de http://desgenerandoelgenero.blogspot.com/2013/05/ una-respuesta-sexismo-linguistico-y.html

Carbajal, M. (15 de junio de 2012). Ni una mujer más quemada. En: Suplemento SOY. Página/12. Recuperado a partir de https://www.pagina12.com.ar/diario/sociedad/3-196432-2012-06-15.html

Carrasco Calero, J. L. (2007). Guía sobre comunicación socioambiental con perspectiva de género. Consejería de Medio Ambiente, Junta de Andalucía. S/D.

Cooper, R. L. (1997). La planificación lingüistica y el cambio social. Madrid: Cambridge University Press.

De Peretti, C. (1989). Entrevista con Jacques Derrida. Derrida en castellano. Recuperado a partir de https://redapre nderycambiar.com.ar/derrida/textos/derrida_entrevista.htm

Del Valle, J y Arnoux, E. (2010). Las representaciones ideológicas del lenguaje: discurso glotopolítico y panhispanismo. Spanish in Context. 7(1), 1-24.

Del Valle, J. (2011). Política del lenguaje y glotopolítica. España, la RAE y la población latina de Estados Unidos. En S. Senz y A. Montserrat (eds.). El dardo en la Academia. Esencia y vigencia de las academias de la lengua española, 2 vols. (551-590). Barcelona: Melusina.

Del Valle, J. y Stheeman, L. (eds.) (2004). La batalla del idioma. La intelectualidad hispánica ante la lengua. Madrid: Iberoamericana.

Deleuze, G. y Guattari, F. (2002 [1972]). Mil mesetas. Capitalismo y esquizofrenia. Valencia: Pre-textos.

Dirección General de la Mujer y por la Igualdad (2009). Igualdad, lenguaje y Administración: propuestas para un uso no sexista del lenguaje. Conselleria de Bienestar Social, Generalitat Valenciana.

Ennis, J. A. (2008). Decir la lengua. Debates ideológico-lingüisticos en la Argentina desde 1837. Frankfurt am Main: Peter Lang.

Errington, J. (2008). Linguistics in a Colonial World. Michigan: Wiley-Blackwell. 
Fernández Rivero, J. (18 de junio de 2017). La lengua no tiene sexo: 'Elle está cansade. El español. Recuperado a partir de https://www.elespanol.com/cultura/20170617/224478043_0.html

Foucault, M. (1998 [1984]). Historia de la sexualidad I. La voluntad de saber. México: FCE.

Foucault, M. (2008 [1975]). Vigilar y castigar. Buenos Aires: Siglo XXI.

Lagarde, M. (1997). Identidad de género y derechos humanos: la construcción de las humanas. VII Curso de Verano. Educación, Democracia y Nueva Ciudadanía. Aguascalientes: Universidad Autónoma de Aguascalientes.

Lauría, D. (2015). La lengua diccionarizada: Notas sobre la producción lexicográfica del español de la Argentina. El Toldo de Astier, 6(11), 69-77. Recuperado a partir de http://www.memoria.fahce.unlp.edu.ar/art_revistas/pr.6 946/pr.6946.pdf

Lerner, G. (1990). La creación del patriarcado. Barcelona: Crítica.

Marías, J. (9 de septiembre de 2017a). Feminismo antifeminista. Elpaís semanal. Recuperado a partir de https://elpa is.com/elpais/2017/09/10/eps/1504994710_150499.html

Marías, J. (24 de junio de 2017b). Más daño que beneficio. El país semanal. Recuperado a partir de https://elpais.co m/elpais/2017/06/25/eps/1498341938_149834.html

Marías, J. (11 de marzo de 2018a). También uno se harta. Javier Marías Blog. Recuperado a partir de https://javierm ariasblog.wordpress.com/2018/03/11/la-zona-fantasma-11-de-marzo-de-2018-tambien-uno-se-harta/

Marías, J. (11 de febrero de 2018b). Ojo con la barra libre. El país semanal. Recuperado a partir de https://elpais.com /elpais/2018/02/02/eps/1517571327_169234.html?id_externo_rsoc=TW_CM

Moreno, M. (12 de mayo de 2019). Sin aduana ni peaje, Página /12. Recuperado a partir de https://www.pagina12. com.ar/193244-sin-aduana-ni-peaje

Niklison, L. (2020) (en prensa). Lo que la RAE no nombra no existe: una mirada glotopolítica a las respuestas de la RAE al lenguaje inclusivo/no sexista. Cuadernos de la ALFAL, 12 (1).

Pérez-Reverte, A. [@perezreverte]. (14 de enero de 2012) Feminazi: ultrafeminista radical que con su estupidez talibán suele estropear la causa noble y justa del feminismo (DRMV). [Tweet]. Twitter. https://twitter.com/perezrev erte/status/158266092354142208

Phillips, W. (2003). Can quirks of grammar affect the way you think? Grammatical gender and object concepts. MIT Journal.S/D.

Real Academia Española. [@RAEinforma]. (5 de agosto de 2019) Ya está en estudio la incorporación de la voz 'transgénero' y del acortamiento 'trans' en próximas actualizaciones del DLE. [Tweet]. Twitter. https://twitter .com/RAEinforma/status/1158344167946432512

Real Academia Española y Asociación de Academias de la Lengua Española (2014). Diccionario de la lengua española (23. a edición). Madrid: Espasa.

Rose, S., Lewotin, R. y Kamin, L. (1990). Not in Our Genes: Biology, Ideology and Human Nature. New York: Penguin Books LTD.

Ruiz Mateo, E. (6 de marzo de 2012). Pérez-Reverte y el sexismo lingüístico. Estandarte. Recuperado a partir de https ://www.estandarte.com/noticias/idioma-espanol/prezreverte-sexismo-lingstico-y-feminismo_1096.html

Russel, D. (1980). Crimes Against Women: Proceedings of the International Tribunal. New York: Frog in the well.

Sarlo, B. (12 de octubre de 2018). Alumnos, alumnas y 'alumnes'. El pais. Recuperado a partir de https://elpais.com/ cultura/2018/10/09/babelia/1539083839_285133.html

Sarlo, B. y Kalinowski, S. (2019). La lengua en disputa. Un debate sobre el lenguaje inclusivo. Buenos Aires: Godot.

Stout, J. G. y Dasgupta, N. (2011). When he doesn't mean you: gender-exclusive language as ostracism. Sage Journal, $37(6)$.

UNED (2012). Guía de lenguaje no sexista. Oficina de Igualdad. S/D.

Universidad Autónoma de Barcelona (2011). Guía para un uso no sexista del lenguaje en la Universitat Autónoma de Barcelona, Servicio de Lenguas de la UAB. Observatorio para la Igualdad de la UAB. S/D. 
Universidad de Alicante (2011). Guía para un discurso igualitario en la Universidad de Alicante. Unidad de Igualdad, Centro de Estudios sobre la Mujer.

Universidad de Cantabria (S/D). Guía de uso del lenguaje no sexista. Vicerrectorado de Campus y Desarrollo Social. S/D.

Universidad de Granada (2010). Guía de lenguaje no sexista, Unidad de Igualdad. S/D.

Universidad de Murcia (2011). Guía de uso no sexista del vocabulario español. S/D. Unidad para la Igualdad entre Mujeres y Hombres. S/D.

Universidad de Salamanca (2012). Guía de igualdad. 1) Líneas básicas del plan de igualdad entre mujeres y hombres de la Universidad de Salamanca, y 2) de la utilización de un lenguaje inclusivo. Unidad de Igualdad. S/D.

Universidad de Valencia (2009). Hacia la igualdad desde el lenguaje. Guía para un uso no sexista del lenguaje. Unidad de Igualdad. S/D.

Universidad del País Vasco (2008). Guía para un uso no sexista de la lengua castellana y de imágenes en la UPV/EHU, Dirección para la Igualdad de la UPV.

Universidad Politécnica de Madrid (2010). Manual de lenguaje no sexista en la Universidad Politécnica de Madrid. Unidad de Igualdad. S/D.

Universitat Jaume I (2011). Guía de tratamiento no sexista de la información y la comunicación en la Universitat Jaume I, Unidad de Igualdad. S/D.

\section{Notas}

1 En función del posicionamiento metodológico de este trabajo y entendiendo que en ningún caso la representación de un cierto deber ser propio de las academias de la lengua pueden ser neutrales, se define en este trabajo que las designaciones en plural de colectivos de personas serán nombradas con lenguaje no binario o lenguaje inclusivo. La forma de utilizarlo será la letra "e" en reemplazo de la "o" del mal llamado "masculino genérico": el objetivo es ejercer en la redacción del propio trabajo una transformación que se sostiene dentro de él como parte necesaria del avance de los movimientos feministas en la lucha contra las desigualdades de género, también desde el lenguaje.

2 Según indica la aplicación PlayStore en la información de la aplicación al mes de enero de 2020.

3 La utilización de la frase nominal "lenguaje inclusivo" se utiliza aquí para simplificar. Mientras que la totalidad de los manuales aquí citados como referencias de materiales de uso no utilizan este término sino el de "lenguaje no sexista", la frase "lenguaje inclusivo" se utiliza mucho más extendidamente en la prensa gráfica, en debates televisivos, en blogs, y en cierto sentido común extendido. Sin embargo, la referencia al "lenguaje inclusivo" suele traer aparejada una discusión específica: la de la transformación de la morfología del género del español para incluir una forma que no utilice ni la "a" asociada al femenino ni la "o" asociada al masculino, sino otra letra o signo, ya sea este una cruz ("todxs") o una e ("todes"). La designación de "lenguaje inclusivo" para hablar de estas transformaciones morfológicas es nombrada, aunque con menos frecuencia, también de otra forma: se le dice "lenguaje no binario" y nombra la importancia de nombrar a los colectivos de una manera en la que no sea necesario catalogar a las personas en dos categorías, sino escapar a los binarismos con nuevas formas de decir. María Moreno (2019) se ha pronunciado a este respecto en el Congreso Encuentro Internacional de Derechos Lingüísticos como Derechos Humanos exponiendo la importancia de no llamar a esta transformación en la lengua "lenguaje inclusivo": "Claro que estoy totalmente en contra del lenguaje inclusivo. Quiero decir, de la expresión "lenguaje inclusivo". Porque ¿quién incluye? ¿Desde qué centro de su magnanimidad, aunque sin coronita, levanta la barrera, firma el pasaporte y bienviene a través de e o x?". Moreno propone en cambio llamarlo "lenguaje descentrado", un lenguaje "sin aduana ni peaje, desalambrado, tuttifruti, culeado, es decir, donde cualquier palabra entre y salga con jugoso placer, sin Academia que valga, por la emancipación” (Moreno, M. (2019), cf. Bibliografía). En este trabajo, la denominación "lenguaje inclusivo" busca contener todos estos debates en un nombre reconocible fácilmente para cualquier persona que haya escuchado alguna vez debates en torno a esta temática, y se busca con él meramente simplificar la remisión a esta cuestión.

4 Cf. en Bibliografía: Carrasco Calero, J. L. (2007); Bravo Sueskun, C. (2010); Dirección General de la Mujer y por la Igualdad (2009); Universidad del País Vasco (2008); Universidad de Valencia (2009); Universidad de Granada (2010); Universidad Politécnica de Madrid (2010); Universidad Autónoma de Barcelona (2011); Universitat Jaume I (2011); Universidad de Alicante (2011); Universidad de Murcia (2011); Universidad de Cantabria (S/D); UNED (2012); Universidad de Salamanca (2012). 
5 En la política argentina ocurrió un evento menor que puso de manifiesto la frecuencia con la que se confunden las categorías de sexo y género, incluso refiriéndose este último al género gramatical. Durante una sesión extraordinaria de la Honorable Cámara de Senadores de la Nación el 20 de diciembre de 2019, el jefe de la bancada peronista José Mayans dijo "así que, presidente, solicito que se vote el proyecto". La presidenta del Senado, Cristina Fernández, le respondió al senador diciéndole "presidenta, presidenta”, haciendo énfasis en la última sílaba de la palabra, e insistiendo luego, "ta, ta”. Ante la reacción de la presidenta, el senador Mayans contestó que "no tiene sexo la palabra presidente", frente a lo cual Cristina Fernández declaró: “no, no, no. Eso lo dicen los machistas”. Más allá de lo anecdótico de la irrupción de un debate sobre política lingüística en el medio de una sesión del Senado que no tenía que ver con la lengua, vale la pena hacer énfasis en que el argumento del senador Mayans no se centró en el género ¿neutro? del participio presente activo "presidente", sino en decir que la palabra "presidente” no tenía sexo. La equiparación del sexo (fenotípico, cromosómico, hormonal, el que sea, en fin: humano) con el género gramatical de una palabra lleva a pensar en una cierta naturalización de que los géneros masculino y femenino (que la morfología del español asigna a los sustantivos) replican ciertas características vinculadas con el género (impuesto a las personas como constructo sociocultural en base a su genitalidad) en aquello que se nombra según el género gramatical de una u otra forma. A propósito de esto se produjo un encendido debate en la red social Twitter, donde la RAE fue consultada varias veces. Frente a las diversas preguntas sobre si el uso de "presidenta" era admitido por la Academia, los tuits que respondieron fueron más o menos siempre iguales: “\#RAEconsultas Aunque «presidente» puede usarse como común en cuanto al género («el/la presidente»), es preferible hoy usar el femenino morfemático «presidenta», documentado en español desde el siglo XV y registrado en el diccionario académico desde 1803." (Real Academia Española, 20/12/2019 [Tweet]. Extraído de: www.twitter.com).

6 Sexo biológico refiere al "conjunto de características biológicas (pene, vagina, hormonas, etc) que determinan lo que es un macho o una hembra en la especie humana. Al nacer, a las personas se les asigna un sexo de acuerdo a estas características" (extraído del sitio web de Fundación Huésped. Disponible en: https://www.huesped.org.ar/informaci on/derechos-sexuales-y-reproductivos/tus-derechos/diversidad-sexual-y-genero/).

7 El primer uso registrado corresponde al periodista estadounidense Rush Limbaugh, que desde 1992 pretendió promover su uso para desacreditar al feminismo, con poco éxito. Su uso se popularizó a partir de un extendido uso en las redes.

8 Se cita aquí el intercambio entre la cuenta oficial de la Real Academia Española y el usuario Aly (2016/7/7): “\#RAEconsultas Sí se dice que es un término despectivo, acuñado como acrónimo de 'feminista' + 'nazi' y es de reciente aparición”; Aly (2016/16/9). “¿Cuál es el término correcto para referirse a una mujer que defiende la superioridad de la mujer?@RAEinforma”; Real Academia Española (2016/16/9). “\#RAEconsultas 'Hembrismo' se usa en los textos como opuesto a 'machismo'; es neologismo reciente y no figura en el diccionario”. Extraído de: http://www.twitter.com.

9 Se hace referencia aquí a reiteradas consultas al portal UNIDRAE (https://www.rae.es/formulario/unidrae), consultado el 12/3/2018: cerrado; consultado el 27/3/2018: cerrado; consultado el 11/6/2019: cerrado; consultado el 21/9/2019: cerrado; consultado el 20/2/2020: disponible.

10 Frecuentemente la Real Academia Española a través de su cuenta @RAEinforma ha respondido a consultas con respecto al vocablo "trans" para referirse a un colectivo de diversas identidades sexogenéricas no-cisexuales, como este del 21 de enero de 2020: “Ya está en estudio la incorporación de la voz 'transgénero' y del acortamiento 'trans' en próximas actualizaciones del DLE”. [Tweet]. Extraído de: http://www.twitter.com

11 Se acuerda aquí con la definición de "panhispanismo" de Del Valle y Arnoux (2010): un producto de una política de área idiomática encabezada por España que busca instalar una serie de ideologemas, a saber: que la lengua es una patria común; que la lengua es un lugar de encuentro; que el español es una lengua universal; que el español es una lengua mestiza; entre otros.

\section{BY-NC-SA}

